ISSN pr. 2412-608X, ISSN on. 2412-6098

Масличные культуры.

ВыII. 3 (183), 2020

\section{Селекционные достижения}

УдК 631.52:633.854.78

DOI: 10.25230/2412-608X-2020-3-183-157-160

\section{Трёхлинейный гибрид подсолнечника Ника}

\author{
О.Ф. Горбаченко, \\ директор, д-р с.-х. наук \\ Ф.И. Горбаченко, \\ зав. отделом, д-р с.-х. наук, профессор \\ В.Д. Горбаченко, \\ зав. лабораторией, канд. с.-х. наук \\ Т.В. Усатенко, \\ зав. лабораторией, стар. науч. сотрудник \\ Н.С. Лучкин, \\ зав. лабораторией, стар. науч. сотрудник \\ Н.А. Житник, \\ зав. лабораторией, науч. сотрудник \\ Е.Г. Бурляева, \\ науч. сотрудник \\ Донская опытная станция (ДОС) - филиал \\ ФГБНУ ФНЦ ВНИИМК \\ Россия, 346754, Ростовская область, Азовский \\ район, пос. Опорный, ул. Жданова, 2 \\ Тел.: (86342) 75-1-21 \\ E-mail: gnudos@mail.ru
}

Для цитирования: Горбаченко О.Ф., Горбаченко Ф.И., Горбаченко В.Д., Усатенко Т.В., Лучкин Н.С., Житник Н.А., Бурляева Е.Г. Трёхлинейный гибрид подсолнечника Ника // Масличные культуры. - 2020. - Вып. 3 (183). - С. 157-160.

Ключевые слова: подсолнечник, трёхлинейный гибрид, урожайность, устойчивость к заразихе и ложной мучнистой росе, регионы допуска.

Трёхлинейный гибрид подсолнечника Ника создан на Донской опытной станции - филиал ФГБНУ ФНЦ ВНИИМК методом гибридизации простого стерильного гибрида Донской 59 и линии восстановителя фертильности пыльцы ЭД 155. Характеризуется высокой продуктивностью, за годы испытания он превысил контроль по урожаю семян на 0,29 т/га, по сбору масла - на 0,18 т/га. По длине вегетационного периода (98-104 суток) его можно отнести к среднераннепелой группе. Высота растений 170-180 см. Листья крупные, пузырчатость очень слабая, зубчатость крупная. Корзинки среднего размера, при созревании повёрнутые вниз с прямым стеблем. Семянки широкояйцевидной формы, чёрные с серыми полосками по краям и между краями. Основной отличительной чертой гибрида является его высокая продуктивность и устойчивость к новым агрессивным расам заразихи $(\mathrm{E}, \mathrm{F}, \mathrm{G})$ и ложной мучнистой росы (раса 330 ). Гибрид Ника внесён в государственный реестр охраняемых селекционных достижений РФ с 2019 г. и допущен к возделыванию в 5, 6, 7, 8, 9, 10 регионах России.

\section{UDC 631.52:633.854.78}

Three-line hybrid of sunflower Nika

O.F. Gorbachenko, doctor of agriculture, director

F.I. Gorbachenko, doctor of agriculture, prof., head of the lab.

V.D. Gorbachenko, $\mathrm{PhD}$ in agriculture, head of the lab.

T.V. Usatenko, senior researcher, head of the lab.

N.S. Luchkin, senior researcher, head of the lab.

N.A. Zhitnik, researcher, head of the lab.

E.G. Burlayeva, researcher

Don experimental station (DOS) - a branch of the V.S. Pustovoit All-Russian Research Institute of Oil Crops

2 Zhdanov str., Oporny settl., Azovsky district, Rostov region, 346754 , Russia

Tel.: (86342)75-1-21

E-mail: gnudos@mail.ru

Key words: sunflower, three-line hybrid, yield, resistance to broomrape and downy mildew, released regions.

A three-line sunflower hybrid Nika was developed by hybridization of a simple sterile hybrid Donskoy 59 and a line-restorer of pollen fertility ED 155 at the Don experimental station. It is characterized by high productivity, over the years of testing, it exceeded the control on seed yield by $0.25 \mathrm{t}$ per ha, on oil collection per hectare by $0.16 \mathrm{t}$ per ha. According to the length of the vegetative period (98-104 days), it can be attributed to the middle-early group. Plant height is up to $170-180 \mathrm{~cm}$. The leaves are large, the bubbling is very weak, and serration is large. Heads of medium size when maturing turned down with a straight stem. Achenes are broadly ovate, black with grey stripes along the edges and between the edges. The main distinguishing feature of the hybrid is its high productivity and resistance to the new aggressive races of broomrape (E, F, G) and downy mildew (race 330). The hybrid Nika has been included into the State register of protected breeding achievements of the Russian Federation since 2019 and allowed to be cultivated in the Central Black Soil (5), Northern Caucasus (6), Middle Volga (7), Low Volga (8), Ural (9), and Western Siberian (10) regions of Russia.

Подсолнечник - основная масличная культура России. Посевные площади его в 2019 г. составили 8,5 млн га. Основными требованиями, предъявляемыми производством к современным гибридам подсолнечника, являются высокая ста- 
бильная продуктивность и устойчивость к болезням и заразихе. По мнению академика А.А. Жученко, вариабельность урожайности сельскохозяйственных культур по годам на 50-80 \% зависит от сложившихся погодных условий [5]. Чтобы противостоять действию неблагоприятных абиотических и биотических стрессов, необходимо создавать гибриды, которые наиболее эффективно могут использовать местные условия внешней среды. Исследования, проведённые во ВНИИМК, выявили, что трёхлинейные гибриды подсолнечника, имеющие более широкую генетическую основу по сравнению с простыми гибридами, существенно уменьшают колебания урожайности по годам в различных климатических условиях, повышая стабильность производства товарных семян [2]. Такие же данные получены и другими исследователями [3]. Большой вклад в стратегию селекционно семеноводческой работы вносит и необходимость учёта рентабельности гибридного семеноводства подсолнечника. По мнению учёных, главным фактором, определяющим экономическую эффективность гибридного семеноводства, является выход семян с 1 га участка гибридизации [3]. Стоимость семян простых гибридов F1 составляет до 30 \% затрат при возделывании товарного подсолнечника [1]. Тройные гибриды, материнскими формами которых являются простые стерильные гибриды, в этом плане находятся в выгодном положении. Показатели урожайности семян на участках гибридизации у них выше в 2 раза, чем у простых гибридов [4]. Таким образом, более высокая стабильность урожайности семян в зависимости от погодных условий и высокая рентабельность семеноводства тройных гибридов определяют экономическую необходимость их использования.

Селекционные работы по получению трехлинейных гибридов на Донской опытной станции станции (Ростовская область, Азовский район) были начаты ещё в конце XX века. В первые годы про- водились работы по получению простых стерильных гибридов, изучению их комбинационной способности и отбору самых перспективных. При их скрещивании с линиями-восстановителями фертильности пыльцы создавали трёхлинейные гибридные комбинации. Лучшие из них передавали в государственное сортоиспытание. После их оценки они были внесены в государственные реестры допущенных к использованию и охраняемых селекционных достижений: Мечта (2004), Призёр (2005), Дон РА (2006).

В связи с широким распространением на посевах подсолнечника новых более агрессивных рас заразихи и ложной мучнистой росы, возникла необходимость создания трёхлинейных гибридов подсолнечника, устойчивых к этим расам патогенов. Новый трёхлинейный гибрид подсолнечника Ника был передан в государственное испытание с 2017 г. (рис. 1). Он создан методом гибридизации простого стерильного гибрида Донской 59 с линией-восстановителем фертильности пыльцы ЭД 155.

По результатам изучения в условиях станции его можно отнести к среднераннеспелой группе (длина вегетационного периода от всходов до созревания 98104 суток). Высота растений 170-180 cм, стебель устойчив к полеганию.

Гибрид высокопродуктивный, потенциальная урожайность семян 3,5-4,0 т/га. По этому показателю он превысил контроль, трёхлинейный гибрид Дон $\mathrm{Pa}$, на 0,29 т/га, а по сбору масла - на 0,18 т/га. По содержанию масла в семенах (50,8 \%), лузжистости $(25,8 \%)$ и массе 1000 семян $(60,8$ г) он практически на одном уровне с контролем (таблица).

Основная отличительная особенность гибрида - высокая продуктивность и устойчивость к высоковирулентным расам заразихи $(\mathrm{E}, \mathrm{F}, \mathrm{G})$ и ложной мучнистой росы (330), что подтверждено при оценке в условиях искусственного заражения. В полевых условиях гибрид слабо поража- 
ется ржавчиной, вертициллёзом, проявляет толерантность к фомопсису, не повреждается подсолнечной огнёвкой, засухоустойчив.

Таблица

\section{Показатели хозяйственно ценных} признаков гибрида подсолнечника Ника

ДОС - филиал ФГБНУ ФНЦ ВНИИМК,

\begin{tabular}{|c|c|c|c|c|c|c|c|c|c|c|c|}
\hline \multirow[b]{2}{*}{$\begin{array}{c}\text { Гиб- } \\
\text { рид }\end{array}$} & \multirow{2}{*}{$\begin{array}{c}\text { Веге- } \\
\text { таци- } \\
\text { он- } \\
\text { ный } \\
\text { пери- } \\
\text { од от } \\
\text { всхо- } \\
\text { дов до } \\
\text { созре- } \\
\text { вания, } \\
\text { сутки }\end{array}$} & \multicolumn{2}{|c|}{$\begin{array}{l}\text { Урожай- } \\
\text { ность } \\
\text { семян, }\end{array}$} & \multicolumn{2}{|c|}{$\begin{array}{c}\text { Сбор } \\
\text { масла, }\end{array}$} & \multirow[b]{2}{*}{$\begin{array}{c}\text { Мас- } \\
\text { лич- } \\
\text { ность, } \\
\%\end{array}$} & \multirow[b]{2}{*}{\begin{tabular}{|c|} 
Луз- \\
жис- \\
тость, \\
$\%$
\end{tabular}} & \multirow{2}{*}{$\begin{array}{c}\text { Mac- } \\
\text { ca } \\
1000 \\
\text { ce- } \\
\text { Мян, } \\
\Gamma\end{array}$} & \multirow{2}{*}{\begin{tabular}{|c} 
Вы- \\
сота \\
рас- \\
те- \\
ния, \\
см
\end{tabular}} & \multicolumn{2}{|c|}{$\begin{array}{c}\text { Поражение } \\
\text { при искусст- } \\
\text { венном } \\
\text { заражении }\end{array}$} \\
\hline & & т/га & $\begin{array}{c} \pm \text { к } \\
\text { конг- } \\
\text { ро- } \\
\text { лю, } \\
\text { т/га }\end{array}$ & $\mathrm{T} / \mathrm{\Gamma a}$ & \begin{tabular}{|c} 
\pm к \\
конт- \\
ро- \\
лю, \\
т/га
\end{tabular} & & & & & $\begin{array}{c}\text { зара- } \\
\text { зи- } \\
\text { хой, } \\
\%\end{array}$ & $\begin{array}{c}\text { ЛМР, } \\
\%\end{array}$ \\
\hline Ника & 101 & 3,70 & $+0,29$ & 1,69 & $+0,18$ & 50,8 & 25,8 & 60,8 & 170 & 2,7 & 0 \\
\hline $\begin{array}{l}\text { Дон Ра } \\
\text { (конт- } \\
\text { роль) }\end{array}$ & 103 & 3,41 & - & 1,51 & - & 49,4 & 26,1 & 65,8 & 174 & 100,0 & 0 \\
\hline $\mathrm{HCP}_{05}$ & & 0,13 & & 0,06 & & & & & & & \\
\hline
\end{tabular}

Листья зелёные, крупные, пузырчатость очень слабая, зубчатость крупная, форма верхушек широкотреугольная, угол между самыми нижними боковыми жилками прямой или почти прямой. Язычковые цветки узко-яйцевидной формы, средней длины, жёлтые. Трубчатые цветки жёлтые, без антоциановой окраски рылец пестиков. Листочки обёртки удлинённой формы, очень слабо охватывают корзинку. Корзинки при созревании повёрнутые вниз с прямым стеблем, форма семенной стороны слабовыпуклая (рис. 1). Семянки среднего размера, широкояйцевидной формы, чёрные, краевые полоски и полоски между краями серые (рис. 2).

Материнская форма гибрида Ника простой стерильный гибрид Донской 59 создан методом гибридизации стерильного аналога линии ЭД 169 и фертильного аналога линии ЭД 45 (рис. 3) Вегетационный период в условиях станции от всходов до цветения 56-58 суток, до созревания 94-96 суток. Высота растений 135-140 см. Урожайность семян на участках гибридизации 1,55-1,70 т/га. Масличность семян 48,8-50,0 \%, лузжистость $22,0-23,0 \%$, масса 1000 семян 74,0-76,0 г.

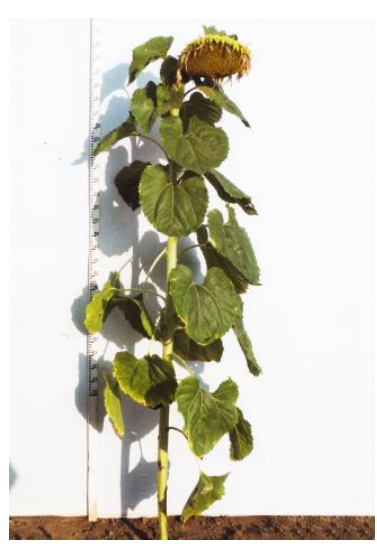

Рисунок 1 - Растение гибрида Ника

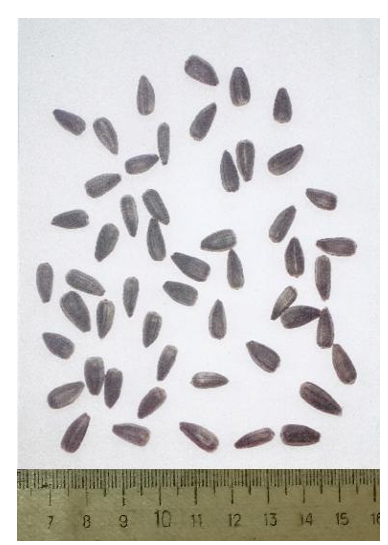

Рисунок 2 - Семена гибрида Ника
Листья среднего размера, зелёные, пузырчатость средняя, зубчатость средняя, размер ушек большой, угол между самыми нижними боковыми жилками прямой или почти прямой. Язычковые цветки средней плотности, широкояйцевидной формы, средней длины, жёлтые, положение в пространстве волнистое. Трубчатые цветки жёлтые, без антоциановой окраски рылец пестиков. Листочки обёртки округлой формы, средней длины, при созревании слабо охватывают корзинку. Корзинки среднего размера, форма семенной стороны слабовыпуклая, положение при созревании полуповёрнутое вниз с изогнутым стеблем. Семянки среднего размера, широкояйцевидной формы, чёрные, краевые полоски и полоски между краями слабо выражены, серые. Основной отличительной чертой является высокая комбинационная способность. В полевых условиях слабо поражается ржавчиной, вертициллёзом, не повреждается подсолнечной огнёвкой. Простой стерильный гибрид Донской 59 внесён в Государственные реестры допущенных к использованию и охраняемых селекционных достижений РФ.

Отцовская линия гибрида Ника ЭД 155 выделена из синтетика с помощью многократного самоопыления и оценки на устойчивость к заразихе и ложной мучнистой росе (рис. 4). Вегетационный период 
от всходов до цветения 57-59 суток, до созревания - 89-92 суток. Масличность семян 48,0-49,0 \%, лузжистость 28,0-29,2 $\%$, масса 1000 семян 35,0-39,0 г.

Линия ветвистая, ветвление преимущественно верхушечное. Центральная корзинка хорошо развита, расположена ниже наивысшей боковой корзинки. Семянки узкояйцевидной формы, черные, полоски по краям и между краями слабо выраженные, серые. Основной отличительной чертой линии является устойчивость к комплексу рас заразихи (A, B, C, $\mathrm{D}, \mathrm{E}, \mathrm{F}, \mathrm{G})$ и ложной мучнистой росы (330). В полевых условиях линия не поражается вертициллезом, альтернариозом, ржавчиной, не повреждается подсолнечной огневкой. Линия внесена в Государственные реестры допущенных к использованию и охраняемых селекционных достижений РФ.

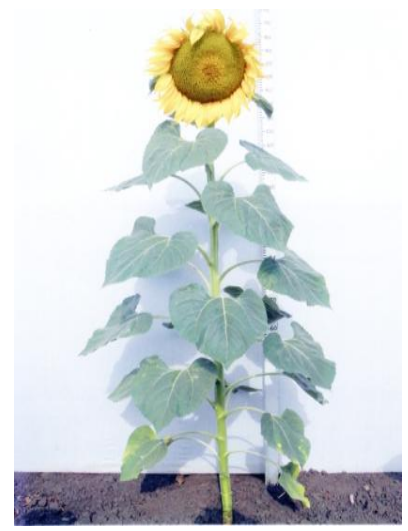

Рисунок 3 -

Стерильный гибрид

Донской 59

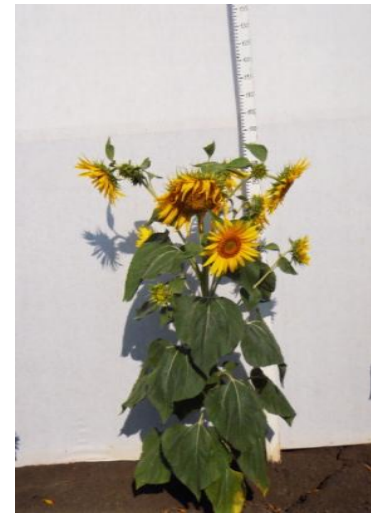

Рисунок 4 -

Отцовская линия ЭД 155
Гибрид Ника допущен к использованию по Центрально-Черноземному, Северо-Кавказскому, Средневолжскому, Нижневолжскому, Уральскому, Западно-Сибирскому регионам и внесён в государственный реестр охраняемых селекционных достижений РФ с 2019 г. Оригинаторы гибрида - ФГБНУ ФНЦ ВНИИМК и ООО «Агропромышленная фирма «Элита Дона».
В производственных посевах зоны недостаточного увлажнения густота стояния растений трёхлинейного гибрида Ника 50-55 тыс./га к уборке, а при хорошей влагообеспеченности ее можно увеличить на $10-15 \%$.

\section{Список литературы}

1. Беккер $X$. Селекция растений. - М.: Товарищество научных изданий КМК, 2015. -425 с.

2. Бочковой А.Д., Савченко В.Д. Сравнительная характеристика простых и трёхлинейных гибридов подсолнечника // Науч.-тех. бюл. ВНИИМК. 1997. - Вып. 118. - С. 19-23.

3. Бочковой А.Д., Хатнянский В.И., Камардин $B . A$. Типы гибридов подсолнечника и особенности их использования в условиях Российской Федерации (обзор) // Масличные культуры. - 2019. Вып. 1 (177). - С. 110-123.

4. Вронских М.Д. Создание специализированных зон семеноводства гибридного подсолнечника: опыт и проблемы // Селекция и семеноводство. 1983. - № 2. - C. 31-34.

5. Жученко А.А. Стратегия адаптивной интенсификации сельского хозяйства (Концепция). Отдел НТИ Пущинского научного центра РАН. Пущино, 1994. - С. 3-5.

\section{References}

1. Bekker X. Selektsiya rasteniy - M.: Tovarishchestvo nauchnykh izdaniy KMK, 2015. - $425 \mathrm{~s}$.

2. Bochkovoy A.D., Savchenko V.D. Sravnitel'naya kharakteristika prostykh i trekhlineynykh gibridov podsolnechnika // Nauch.tekh. byul. VNIIMK. - 1997. - Vyp. 118. - S. 19-23.

3. Bochkovoy A.D., Khatnyanskiy V.I., Kamardin V.A. Tipy gibridov podsolnechnika i osobennosti ikh ispol'zovaniya $\mathrm{v}$ usloviyakh Rossiyskoy Federatsii (obzor) // Maslichnye kul'tury. - 2019. - Vyp. 1 (177). S. 110-123.

4. Vronskikh M.D. Sozdanie spetsializirovannykh zon semenovodstva gibridnogo podsolnechnika: opyt i problemy // Selektsiya i semenovodstvo. - 1983. - № 2. S. 31-34.

5. Zhuchenko A.A. Strategiya adaptivnoy intensifikatsii sel'skogo khozyaystva (Kontseptsiya). Otdel NTI Pushchinskogo nauchnogo tsentra RAN. Pushchino, 1994. -S. 3-5.

Получено: 20.07.2020

Принято: 05.10.2020.

Received: 20.07 .2020 